\title{
Effect of enhancement of selenium content in zirconium sulphoselenide on its photoelectrochemical behaviour
}

\author{
G K Solanki*, Sudeep Goyal, S K Arora, Dipika B Patel and M K Agarwal \\ Department of Physics, Sardar Patel University, \\ Vallabh Vidyanagar-388 120, Gujarat, India \\ E-mail : solankigunvant@yahoo.co.in
}

Received 13 May 2008, accepted 29 September 2008

\begin{abstract}
In this paper, we have attempted to fabricate PEC solar cells with mixed crystals of Zirconium sulphoselenide. Energy band location and redox analysis of the material have been made using Mott-Schottky plots. These studies justify the selection of an appropriate electrolyte for PEC work. Various solar cells fabricated with single crystals of selenium rich and selenium deficient zirconium sulphoselenide have been prepared. The solar cell parameters e.g. the fill factor (FF), open circuit voltage $\left(V_{o c}\right)$, short circuit current $\left(I_{s c}\right)$ and efficiency $(\eta)$ for all the different cells have been determined. In order to see the effect of enhancement of selenium in $\mathrm{ZrS}_{\mathrm{x}} \mathrm{Se}_{2-\mathrm{x}}$ on photoresponse, the electrolyte and intensity of illumination were kept constant and all the electrodes were prepared from crystals showing absolutely plane faces obtained through the act of cleavage with the help of an adhesive tape. The results have been thoroughly analysed and the implications have been discussed.
\end{abstract}

Keywords : Zirconium sulphoselenide; Mott-Schottky plots; PEC solar cells; Fill factor and efficiency.

PACS No. : $\quad 71.20 . \mathrm{Nr}$

\section{Introduction}

The development of photoelectrochemistry, as a field of science, in the past two decades was stimulated largely by the need for working out a photoelectrochemical solar energy conversion method as a new, ecologically clean and inexhaustible source of energy. In the most promising variant of the method of converting light energy into electrical and chemical energy, use is made of PEC cells with semiconductor electrodes. The development of practical PEC cells depends on the availability of suitable electrodes. Keeping this in view, a large number of investigators [1,2] concentrated their efforts on the fabrication of PEC solar cells using transition metal dichalcogenides as photoelectrodes. In this direction,

* Corresponding Author 
attention was focussed on a less explored material i.e. Zirconium Sulphoselenide because of the following technical reasons :

(1) $\mathrm{Zr}$ is a relatively abundant metal.

(2) $\mathrm{ZrS}_{\mathrm{x}} \mathrm{Se}_{2-\mathrm{x}}(0 \leq \mathrm{x} \leq 2)$ possesses a layered type structure with a crystal lattice very similar to $\mathrm{MoS}_{2}$ and band gaps lying between 1.2 and $1.8 \mathrm{eV}$ [3].

(3) Semiconductors of this type should be considered to be potentially suitable in the combined conversion and storage of solar energy.

From literature survey, it appears that so far very few attempts [4] have been made to study the photoelectrochemical behavior of these materials. Patel et al [5] have undertaken experiments to explore the feasibility of zirconium sulphoselenide $\left(\mathrm{ZrS}_{x} \mathrm{Se}_{2-\mathrm{x}}\right.$ with $x=0,1$ and 2) in the fabrication of PEC solar cells. In absence of any PEC work on selenium deficient and selenium rich zirconium sulphoselenide single crystals, authors have carried out a systematic study on the photoelectrochemical behavior of selenium enhanced i.e. $\mathrm{ZrS}_{0.5} \mathrm{Se}_{1.5}$ and selenium deficient $\mathrm{ZrS}_{1.5} \mathrm{Se}_{0.5}$ single crystals of zirconium sulphoselenide. Effect of increasing the concentration of selenium in $\mathrm{ZrS}_{x} \mathrm{Se}_{2-\mathrm{x}}$ on the photoresponse of PEC solar cells fabricated with these crystals as electrodes has been thoroughly studied and the implications of this study have been pointed out.

\section{Experimental}

\subsection{Selection of material :}

Single crystals of $\mathrm{ZrS}_{1.5} \mathrm{Se}_{0.5}$ and $\mathrm{ZrS}_{0.5} \mathrm{Se}_{1.5}$ required for the present work were grown by chemical vapour transport method [6] using iodine as the transporting agent. Care has been taken to select the samples from the same batch. All the crystals when characterized by EDAX for compositional analysis indicated that all of them are non-stoichiometric. Electrical characterization of the samples showed that all of them possess $n$-type semiconducting nature. The n-type nature has been attributed to the non-stiochiometry of the grown samples.

\subsection{Sample preparation:}

Step free van der Waal (vdw) surface i.e. crystals with nearly plane faces were procured after a careful examination of the samples under an 'Epignost' optical microscope. In order to see the effect of increasing selenium concentration in $\mathrm{ZrS}_{\mathrm{x}} \mathrm{Se}_{2-\mathrm{x}}$ on the photoresponse, all the samples of $\mathrm{ZrS}_{1.5} \mathrm{Se}_{0.5}$ and $\mathrm{ZrS}_{0.5} \mathrm{Se}_{1.5}$ were deliberately chosen to be step free. Such surfaces could be easily prepared by the act of cleavage.

\subsection{Solar cell fabrication :}

Semiconductor electrodes using crystals of $\mathrm{ZrS}_{1.5} \mathrm{Se}_{0.5}$ and $\mathrm{ZrS}_{0.5} \mathrm{Se}_{1.5}$ were fabricated in the manner described in [7]. The electrode was immersed in an appropriate electrolyte (to be discussed below) contained in a corning glass beaker. A platinum grid $(3 \mathrm{~cm} \times 3 \mathrm{~cm})$ was used as the counter electrode. A schematic diagram showing the PEC cell is given 
in Figure 1. The cell was illuminated with light from an incandescent lamp. The intensity of illumination was altered by changing the distance of light source from the electrode. The incident intensity of illumination was measured using the light measuring instrument 'Suryamapi' furnished by Central Electronics Limited, India. Photocurrent and photovoltage were recorded using digital multimeters.

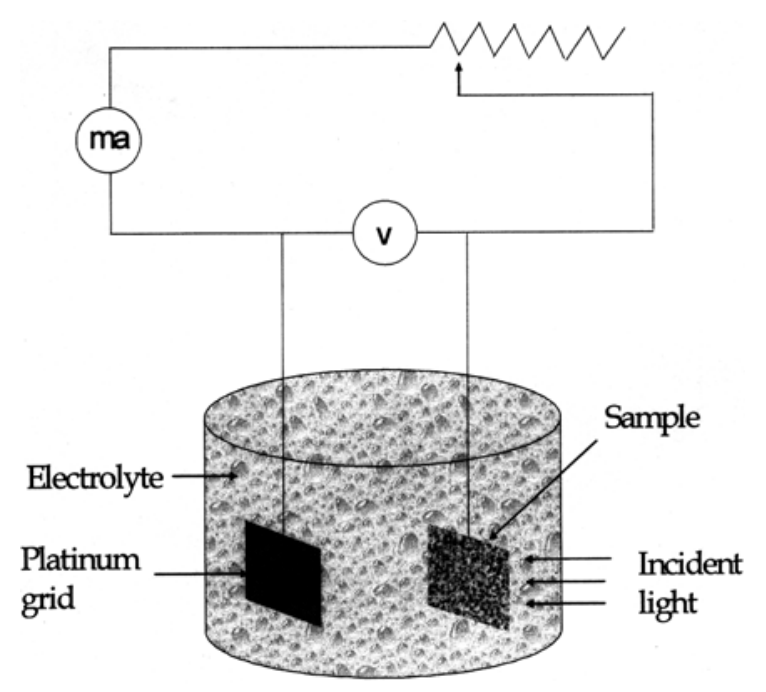

Figure 1. Schematic diagram of PEC solar cell.

\section{Results}

Abruna et al [8] suggested the use of electrolytes with redox couples $I_{3}^{-} / I_{2}$ and Fe (III I II) for $n$-type electrodes. They found that with $\mathrm{Fe}^{3^{+} / 2^{+}}$redox couple electrolyte the PEC response of the electrodes was very poor. Kautek et al [9] showed the importance of support electrolyte mixed with the electrolyte having $I_{3}^{-} / I_{2}$ redox couple. In order to get better photoresponse, Aruna and Bard [10] used various electrolytes with $\mathrm{Na}_{2} \mathrm{SO}_{4}$ as the supporting electrolyte. Since electrolytes using Fe (III / II) redox couple did not give any photoresponse with the $\mathrm{ZrS}_{1.5} \mathrm{Se}_{0.5}$ and $\mathrm{ZrS}_{0.5} \mathrm{Se}_{1.5}$ electrodes, authors tried electrolytes with lodine/lodine redox couple using sodium sulphate and sodium sulphites as supporting electrolytes. It was observed that a mixture of iodine $\left(\mathrm{I}_{2}\right)$, potassium iodide $(\mathrm{KI})$ and sodium metadisulphite $\left(\mathrm{Na}_{2} \mathrm{~S}_{2} \mathrm{O}_{5}\right)$ gave a reasonably good photoresponse.

Thirty different electrolytes with different concentrations of $\mathrm{I}_{2}, \mathrm{KI}$ and $\mathrm{Na}_{2} \mathrm{~S}_{2} \mathrm{O}_{5}$ were therefore prepared. All the chemicals were of reagent grade and the electrolyte solution were prepared using triple distilled water. The solutions were not stirred during the measurements.

Therefore, for determining the optimum electrolyte, photoelectrodes were prepared with $\mathrm{ZrS}_{1.5} \mathrm{Se}_{0.5}$ and $\mathrm{ZrS}_{0.5} \mathrm{Se}_{1.5}$ single crystals having visibly smooth surfaces as obtained by 
an act of cleavage with an adhesive tape. The smoothness of the surfaces was ascertained by an 'Epignost' optical microscope.

Keeping the light intensity at $8 \mathrm{~mW} / \mathrm{cm}^{2}$, dark current ' $I_{D}$ ' dark voltage ' $V_{D}$ ', photovoltage ' $V_{p}$ ' and photocurrent ' $I_{p}$ ' were measured for both $\left(\mathrm{n}-\mathrm{ZrS}_{1.5} \mathrm{Se}_{0.5}\right.$ and $\left.\mathrm{n}-\mathrm{ZrS}_{0.5} \mathrm{Se}_{1.5}\right)$ electrodes in all the electrolytes and it was observed that electrolyte with the composition $0.05 \mathrm{MI}_{2}$ $+1 \mathrm{MKI}+1 \mathrm{MNa}_{2} \mathrm{~S}_{2} \mathrm{O}_{5}$ gave the minimum dark voltage $V_{D}$ and dark current $I_{D}$ and as well provided the maximum value of photocurrent and photovoltage for both the electrodes.

The suitability of this electrolyte for the electrodes giving maximum photoresponse was also ascertained from the Mott-Schottky plots described below.

Mott-Schottky plots $\left(1 /\left(C_{S C}^{2}\right)\right.$ versus $\left.V_{S C E}\right)$ for $\mathrm{n}-\mathrm{ZrS}_{1.5} \mathrm{Se}_{0.5}$ and $\mathrm{n}-\mathrm{ZrS}_{0.5} \mathrm{Se}_{1.5}$ single crystal electrodes are shown in Figure 2 in the electrolyte $0.05 \mathrm{Ml}_{2}+1 \mathrm{MKI}+1 \mathrm{MNa}_{2} \mathrm{~S}_{2} \mathrm{O}_{5}$.

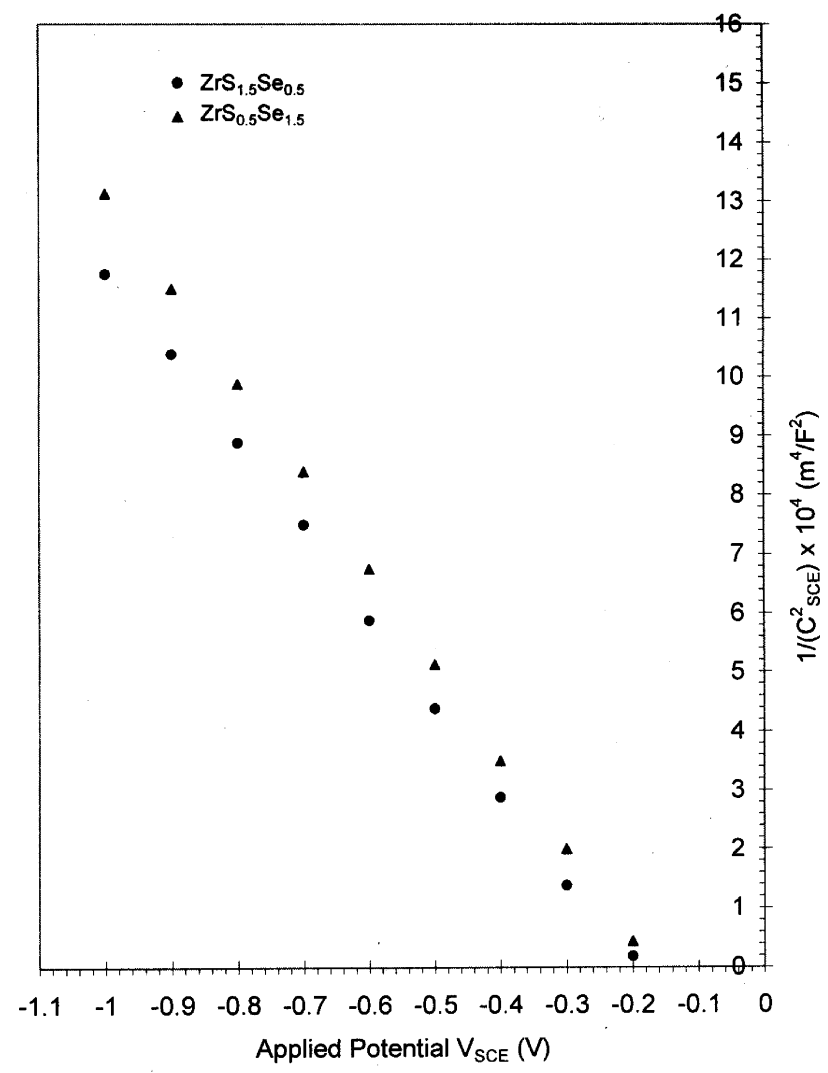

Figure 2. Mott-Schottky plots for $\mathrm{ZrS}_{1.5} \mathrm{Se}_{0.5}$ and $\mathrm{ZrS}_{0.5} \mathrm{Se}_{1.5}$ single crystal electrodes.

In the graphs of $\quad$ versus $V_{S C E}$ for $\mathrm{ZrS}_{1.5} \mathrm{Se}_{0.5}$ and $\mathrm{ZrS}_{0.5} \mathrm{Se}_{1.5}$ the voltage axis intercepts give the flat band potential $V_{f b}$ (Table 1 ), which in the present case are obtained as $-0.2 \mathrm{~V}$ for $\mathrm{ZrS}_{1.5} \mathrm{Se}_{0.5}$ and $-0.18 \mathrm{~V}$ for and $\mathrm{ZrS}_{0.5} \mathrm{Se}_{1.5}$. The donor concentration $n_{D}$ for 
$\mathrm{ZrS}_{1.5} \mathrm{Se}_{0.5}$ and $\mathrm{ZrS}_{0.5} \mathrm{Se}_{1.5}$ can be determined from the slopes of the straight line portions of the Mott-Schottky plots in Figure 2 by using the formula :

where $n_{D}$ is the donor concentration $e$ is the electronic charge, $\varepsilon$ is the dielectric constant of the material, is the free-space permittivity $\left(8.854 \times 10^{-12} \mathrm{Fm}^{-1}\right)$.

The dielectric constant $\varepsilon$ for $\mathrm{ZrS}_{1.5} \mathrm{Se}_{0.5}$ and $\mathrm{ZrS}_{0.5} \mathrm{Se}_{1.5}$ crystals has been evaluated by using the relation :

where $C$ is the capacitance, $d$ is the thickness of the crystal and $A$ is the area of contact. The values of $\varepsilon$ using this formula for $Z_{r S}{ }_{1.5} \mathrm{Se}_{0.5}$ and $\mathrm{ZrS}_{0.5} \mathrm{Se}_{1.5}$ are obtained as 10.4 and 8.8 respectively.

Upon inserting the values of all the parameters in eq. (1), the donor concentration $n_{D}$ (Table 1) for $\mathrm{ZrS}_{1.5} \mathrm{Se}_{0.5}$ and $\mathrm{ZrS}_{0.5} \mathrm{Se}_{1.5}$ are obtained as $8.47 \times 10^{23} \mathrm{~m}^{-3}$ and $1.001 \times$ $10^{24} \mathrm{~m}^{-3}$, respectively.

\subsection{Energetic band location :} valence band and conduction band edges for both the electrodes in the electrolyte reported
Ato above can be estimated.

For $n$-type materials, the difference between $E_{c}$ and $E_{F}$ can be obtained from [11] :

$$
\text { For } N_{D}>n_{D}
$$

where $n_{D}$ is the donor concentration (all donor impurities assumed to be completely ionized), $E_{C}$ is the energy at the edge of the conduction band, $E_{F}$ is the Fermi energy and $N_{D}$ is the density of effective states in the conduction band, which is given by

where $m_{e}^{*}$ is the effective mass of electrons.

Taking the values of effective mass of electron for $\mathrm{ZrS}_{1.5} \mathrm{Se}_{0.5}$ and $\mathrm{ZrS}_{0.5} \mathrm{Se}_{1.5}$ from [12], the values of $N_{D}$ (Table 1 ) have been estimated for these crystals as $1.9 \times 10^{24} \mathrm{~m}^{-3}$ and $4.19 \times 10^{25} \mathrm{~m}^{-3}$ respectively. 
Table 1. Summary of the results obtained from the Mott-Schottky plots for $\mathrm{ZrS}_{1.5} \mathrm{Se}_{0.5}$ and $\mathrm{ZrS}_{0.5} \mathrm{Se}_{1.5}$ single crystals.

\begin{tabular}{lcc}
\hline Type & $\mathrm{n}$ & $\mathrm{n}$ \\
\hline Band gap $\left(\mathrm{E}_{\mathrm{g}}\right)(\mathrm{eV})$ & 1.445 & 1.302 \\
Electrolyte used & $0.05 \mathrm{Ml}_{2}+1 \mathrm{MKI}+1 \mathrm{MNa}_{2} \mathrm{~S}_{2} \mathrm{O}_{5}$ \\
Flat band potential $(\mathrm{eV})$ & -0.2 & -0.18 \\
Band bending $\left(\mathrm{V}_{\mathrm{b}}\right)(\mathrm{eV})$ & 0.114 & 0.094 \\
Carrier concentration $\left(\mathrm{m}^{-3}\right)$ & $8.47 \times 10^{23}$ & $1.001 \times 10^{24}$ \\
Density of states in the conduction & $1.9 \times 10^{24}$ & \\
band $\left(\mathrm{m}^{-3}\right)$ & 124.3 & $4.19 \times 10^{25}$ \\
Depletion width $(\mathrm{W})(\AA)$ & 0.2209 & 0.57 \\
Conduction band edge $\left(\mathrm{E}_{\mathrm{c}}\right)(\mathrm{eV})$ & -1.2241 & -1.0254 \\
Valence band edge $\left(\mathrm{E}_{\mathrm{v}}\right)(\mathrm{eV})$ & & -0.086 \\
Redox Fermi level of the electrolyte & -0.086 & \\
$\left(\mathrm{E}_{\mathrm{F}, \text { redox }}\right)$ & & \\
\hline
\end{tabular}

From equation (3), we can write

$$
E_{C}-E_{F}=k T \ln \left(N_{D} / n_{D}\right)
$$

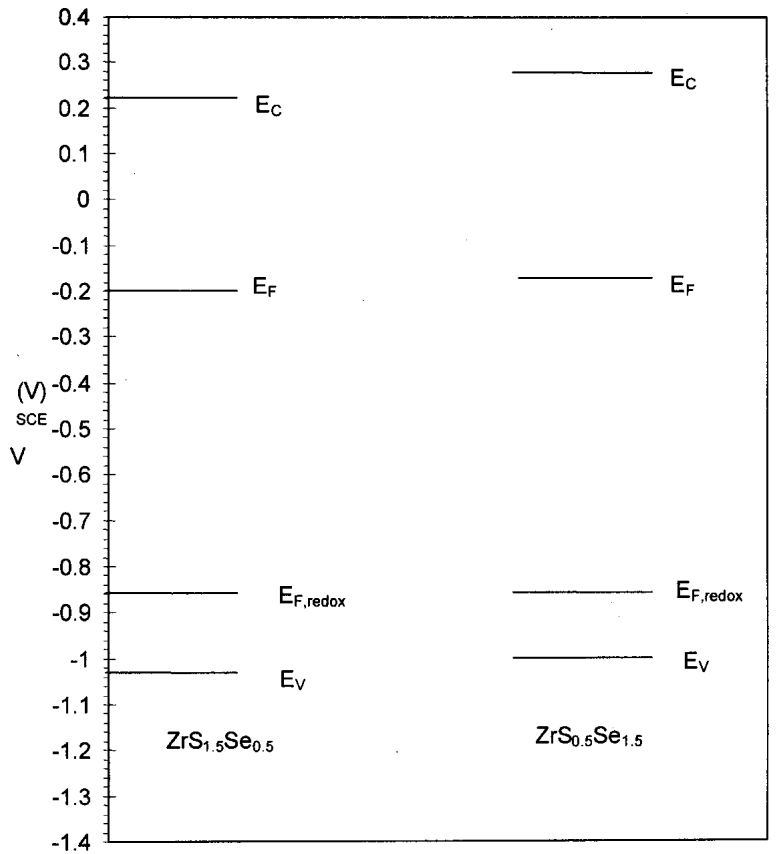

Figure 3. Schematic representation of the energetic location of the conduction and valence bands of $n$ $\mathrm{ZrS}_{1.5} \mathrm{Se}_{0.5}$ and $\mathrm{n}-\mathrm{ZrS}_{0.5} \mathrm{Se}_{1.5}$ single crystals with respect to SCE and the redox system used. 
Using this relation, $E_{C}-E_{F}$ has been evaluated and the values are shown in Table 1. Fromt the values of $V_{f b}$, the values of $E_{C}$ for both the compounds have been estimated and are represented in Table 1. Now, taking the values of energy band gap for $\mathrm{ZrS}_{1.5} \mathrm{Se}_{0.5}$ and $\mathrm{ZrS}_{0.5} \mathrm{Se}_{1.5}$ from [12], the positions of valence band maximum for both the materials have been obtained and are given in Table 1 . The complete energy level diagrams thus obtained for $\mathrm{ZrS}_{1.5} \mathrm{Se}_{0.5}$ and $\mathrm{ZrS}_{0.5} \mathrm{Se}_{1.5}$ in the electrolyte $\left(0.05 \mathrm{MI}_{2}+1 \mathrm{MKI}+1 \mathrm{MNa}_{2} \mathrm{~S}_{2} \mathrm{O}_{5}\right)$ have been prepared and are shown in Figure 3.

The band bending ' $V_{b}$ ' and width of space charge region ' $W$ are related as using the relations [7],

$$
V_{b}=V_{f, \text { redox }}-V_{f b}
$$

$V_{f}$, redox was measured using a $\mathrm{PH}$ meter and a SCE electrode

and

$$
W=2\left(\varepsilon \varepsilon_{0} V_{b} / V_{f b}\right)^{1 / 2}
$$

The values of $V_{b}$ and $W$ have been evaluated for both the electrodes and the values thus obtained are listed in Table 1.

\section{Effect of enhancement of selenium content in zirconium sulphoselenide on the photoresponse in PEC solar cells}

In order to see the effect of enhancement of selenium content in $\mathrm{ZrS}_{x} \mathrm{Se}_{2-x}$ on the photoresponse in the PEC solar cells, the surfaces of both the electrodes i.e. $\mathrm{ZrS}_{1.5} \mathrm{Se}_{0.5}$ and $\mathrm{ZrS}_{0.5} \mathrm{Se}_{1.5}$ were taken after cleaving them with an adhesive tape. Data for

Table 2. Data for photoresponse studies of $n-Z_{1.5} \mathrm{Se}_{0.5}$ and $\mathrm{n}-\mathrm{ZrS}_{0.5} \mathrm{Se}_{1.5}$ single

\begin{tabular}{|c|c|c|}
\hline \multirow[t]{2}{*}{ Particulars } & \multicolumn{2}{|c|}{ Crystal } \\
\hline & $\mathrm{ZrS}_{1.5} \mathrm{Se}_{0.5}$ & $\mathrm{ZrS}_{0.5} \mathrm{Se}_{1.5}$ \\
\hline Type & \multicolumn{2}{|c|}{ n-type } \\
\hline Surface & \multicolumn{2}{|c|}{ Plane obtained after cleaving the as grown face } \\
\hline Contact & \multicolumn{2}{|c|}{ Silver } \\
\hline Intensity of illumination & \multicolumn{2}{|c|}{$8 \mathrm{~mW} / \mathrm{cm}^{2}$} \\
\hline Electrolyte & \multicolumn{2}{|c|}{$0.05 \mathrm{MI}_{2}+1 \mathrm{MKI}+1 \mathrm{MNa}_{2} \mathrm{~S}_{2} \mathrm{O}_{5}$} \\
\hline $\begin{array}{l}\text { Area of the electrode surfaces } \\
\text { exposed }\left(\mathrm{m}^{2}\right)\end{array}$ & $5.47 \times 10^{-6}$ & $5.30 \times 10^{-6}$ \\
\hline Dark Current $I_{D}(\mu A)$ & 0.3 & 0.8 \\
\hline Dark Voltage $V_{D}(m V)$ & 8.9 & 13.7 \\
\hline
\end{tabular}
crystals used as photoelectrodes in PEC solar cells. 
photoresponse studies of these electrodes is given in Table 2 and Table 3 . The solar cell parameters e.g. $I_{s c}, V_{o c}$, the maximum power $\left(P_{\max }\right)$, the voltage at maximum power $\left(V_{\max }\right)$, the fill factor (EF) and the efficiency $(\eta)$ determined from the plots in Figure 3 are represented in Table 3 and Table 4 for $\mathrm{ZrS}_{1.5} \mathrm{Se}_{0.5}$ and $\mathrm{ZrS}_{0.5} \mathrm{Se}_{1.5}$ crystals respectively.

Table 3. Solar cell parameters determined from the J-V characteristics for PEC solar cells fabricated with $\mathrm{ZrS}_{1.5} \mathrm{Se}_{0.5}$ and $\mathrm{ZrS}_{0.5} \mathrm{Se}_{1.5}$ single crystals as photoelectrodes.

\begin{tabular}{lcc}
\hline Parameters & \multicolumn{2}{c}{ Crystal } \\
\cline { 2 - 3 } & $\mathrm{ZrS}_{1.5} \mathrm{Se}_{0.5}$ & $\mathrm{ZrS}_{0.5} \mathrm{Se}_{1 / 5}$ \\
\hline $\mathrm{V}_{\mathrm{oc}}(\mathrm{mV})$ & 373 & 398.2 \\
$\mathrm{I}_{\mathrm{SC}}(\mu \mathrm{A})$ & 10.3 & 13.1 \\
$\mathrm{P}_{\max }(\mathrm{nW})$ & 1360.3 & 1908.8 \\
$\eta(\%)$ & 0.31 & 0.45 \\
$\mathrm{~F} \mathrm{~F}$ & 0.35 & 0.36 \\
\hline
\end{tabular}

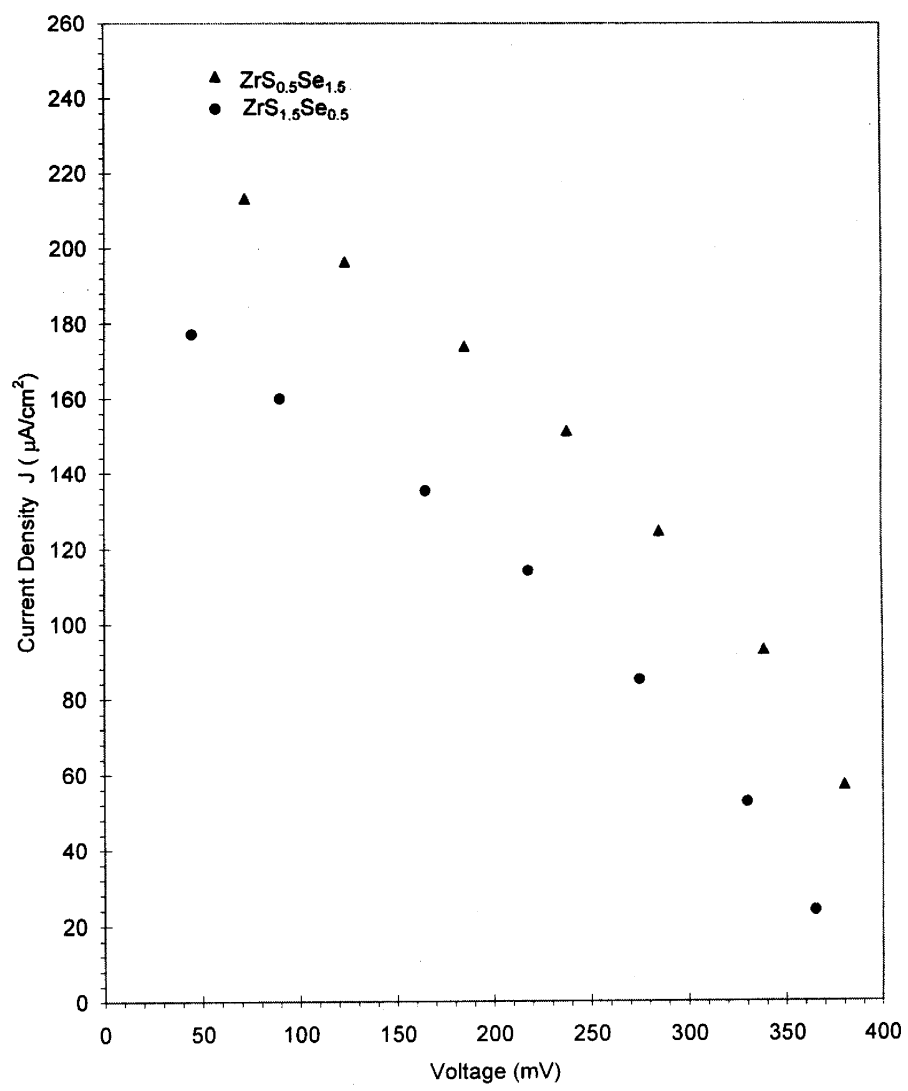

Figure 4. $\mathrm{I}-\mathrm{V}$ Characteristics $\mathrm{ZrS}_{1.5} \mathrm{Se}_{0.5}$ and $\mathrm{ZrS}_{0.5} \mathrm{Se}_{1.5}$ electrodes. 


\section{Discussion}

The nature of Mott-Schottky plots firmly confirms the $n$-type behavior of the single crystals of $\mathrm{ZrS}_{1.5} \mathrm{Se}_{0.5}$ and $\mathrm{ZrS}_{0.5} \mathrm{Se}_{1.5}$ used in the present study. The photoresponse studies carried out in electrolytes of different compositions established that the electrolyte with the composition " $0.05 \mathrm{MI}_{2}+1 \mathrm{MKI}+1 \mathrm{MNa}_{2} \mathrm{~S}_{2} \mathrm{O}_{5}$ " is the most suitable and befitting electrolyte for the present work. The energetic location of the valence and conduction bands carried out above also confirms the suitability of the above electrolyte for both the electrodes, since the redox potential of this electrolyte lies within the band gap.

It is seen from the resistivity measurements [12] on $\mathrm{ZrS}_{\mathrm{x}} \mathrm{Se}_{2-\mathrm{x}}$ that the effect of increasing the selenium concentration is to make the material more conducting and also taking its optical band gap to a value closer to the optimum value for maximum solar energy conversion efficiency. A careful study of the data in Tables 1, 2 and 3 indicates that

1. The band bending ' $V_{b}$ ' and depletion width ' $W$ in sulphur rich $Z \mathrm{ZSS}_{1.5} \mathrm{Se}_{0.5}$ is more pronounced than in the selenium rich $\mathrm{ZrS}_{0.5} \mathrm{Se}_{1.5}$ compound.

2. The photoconversion efficiency ' ' for selenium rich $\mathrm{ZrS}_{0.5} \mathrm{Se}_{1.5}$ is nearly 1.5 times higher than that of the sulphur rich $\mathrm{ZrS}_{1.5} \mathrm{Se}_{0.5}$ compound.

In general, the conversion efficiency of a PEC cell varies with the material properties. Under light excitation the maximum efficiency is given by [13]

where $V_{b}$ is the band bending and $E_{g}$ is the energy gap.

From the above expression it is evident that maximum efficiency depends upon the band bending and $E_{g}$. Thus for an electrochemical cell, the larger the value of band bending, the greater will be the photoconversion efficiency.

In spite of lower values of $V_{b}$ and $W$ in selenium rich compound, the large value of $\eta$ could be due to the lower value of the optical band gap in $\mathrm{ZrS}_{0.5} \mathrm{Se}_{1.5}$. Therefore the increased photoconversion efficiency in $\mathrm{ZrS}_{0.5} \mathrm{Se}_{1.5}$ can be attributed to

(i) Lower value of the band gap ' $E_{g}$ '.

(ii) The lower value of bulk resistivity.

(iii) Higher value of carrier concentration in this sample.

The values of efficiencies so obtained in the present work with $\mathrm{ZrS}_{1.5} \mathrm{Se}_{0.5}$ and $\mathrm{ZrS}_{0.5} \mathrm{Se}_{1.5}$ are, however, too low for any practical utility. But the aim of the present work was to ascertain the effect of enhancement of selenium content on the photoresponse of zirconium sulphoselenide only. 
As a matter of fact PEC solar cells score over their solid state counterparts on several points, some of these being ease of fabrication and inbuilt storage capacity. But, in order to make PEC solar cells viable, their conversion efficiencies have to be enhanced so as to reach optimum values. Several feasible efficiency enhancement proceses for PEC solar cells such as electrode surface modification, photoetching, electrolyte modification etc. have been described and discussed by Pandey et al [14]. Patel et al [15] have also pointed out that a higher degree of surface perfection of the electrode surface is required to obtain high solar energy conversion efficiency from a PEC solar cell. Methods such as selection of electrode surfaces, use of proper ohmic contact, etching of electrode surfaces, use of optimum radiation for illuminating the cell etc. have to be evolved to achieve higher solar to electrical energy conversion from a PEC cell fabricated with a semiconducting crystal.

\section{Conclusions}

It is concluded from the work presented in this paper that enhancement of selenium content in zirconium sulphoselenide single crystals certainly leads to an improved PEC behaviour. But, to obtain a higher (optimum) value of photoconversion efficiency one has to evolve methods e.g. selection of electrode surface and its modification, etching of electrode surface, use of optimum radiation for illuminating the cell etc.

After careful accomplishments of all these steps one can expect a higher value of photoconversion efficiency from selenium rich zirconium sulphoselenide crystals.

\section{References}

[1] H Tributsch Z Naturf. 32 (a) 972 (1977)

[2] A Aruchamy (ed.) Photoelectrochemistry and Photovoltaics of Layered Semiconductors (Dordrecht, Holland/Boston : Kluwer Academic Publishers, USA) (1992)

[3] S G Patel Ph. D. Thesis Sardar Patel University, Vallabh Vidyanagar (1994)

[4] R Memming Electroanalytical Chemistry (ed.) A J Bard (New York : Marcell Dekkar) (1978)

[5] S G Patel, T H Patel and M K Agarwal World Renewable Energy Congress - VI, Brighton, United Kingdom 1-7 July (2000)

[6] H Schafer Chemical Transport Reactions (New York : Academic Press) (1964)

[7] R G Patel, M P Deshpande, S K Arora and M K Agarwal Bull Electrochem. 17 (8) 361 (2001)

[8] H D Abruna, G A Hope and A J Bard J. Electrochem. Soc. 129 (10) 224 (1982)

[9] W Kautek, H Gerischer and H Tributsch J. Electrochem. Soc. 127 (11) 2471 (1980)

[10] H D Abruna and A J Bard J. Electrochem. Soc. 129 (3) 673 (1982)

[11] S Chandra Photoelectrochemical Solar Cells (New York, London : Gordon and Breach Science Publishers) (1985)

[12] Sudip S Goyal Ph. D. Thesis Sardar Patel University, Vallabha Vidyanagar (2002)

[13] K M Garadkar and P P Hankare Int. J. Electrochem. 86 (11) 1311 (1999) and references there in

[14] R N Pandey, K S C Babu and O N Srivastava Prog. Surf. Sci. (U.K.) 52 (3) 125 (1996)

[15] S G Patel, M K Agarwal and D N Gujarathi World Renewable Energy Congress Co. USA p 1521 (1996) 